\title{
More on interpretive factors in forgetting
}

\author{
LYNN HASHER and MARY GRIFFIN \\ Temple University, Philadelphia, Pennsylvania 19122 \\ and \\ MARCLA K. JOHNSON \\ State University of New York, Stony Brook, New York 11790
}

\begin{abstract}
Subjects learned a list of paired associates and reported the elaborators actually used during learning. They also generated "second-choice" elaborators. Both first- and second-choice elaborators were classified as stimulus-related or response-related and given to independent groups of new subjects to use in learning a list of pairs. Over a 1-week retention interval, stimulus-related elaborators produced better retention than did response-related elaborators. There was also some indication that first-choice elaborators were superior to second-choice elaborators.
\end{abstract}

For many years it appeared that only one variable, the degree of original learning, reliably influenced the rate of forgetting of a single laboratory-learned list. Variables such as the use of mnemonics (Olton, 1969), or imposed pictorial elaboration (Forbes \& Reese, 1974), meaningfulness (Underwood \& Richardson, 1956), or concreteness of the materials (Hasher, Riebman, \& Wren, 1976), and age of the subject (Hasher \& Thomas, 1973) all have a dramatic impact upon the speed of learning but no apparent effect on the rate of forgetting. However, recent evidence (Hasher \& Johnson, $1975)$ suggests that retention is affected by some characteristics of the encoding of list items, even when degree of learning is held constant.

Hasher and Johnson (1975) reported two paired associate experiments which suggested that retention is increased if subjects encode a pair primarily in terms of a stimulus-related elaborator. The argument was that, after a considerable delay, a nominal stimulus is more likely to reinstate the functional encoding of a pair if the stimulus had initially determined the encoding. In one study, subjects learned pairs under one of two studytrial procedures: the standard procedure, in which the stimulus and response terms were presented simultaneously, and a modified procedure, in which the stimulus and response occurred separately in succession. Hasher and Johnson found superior retention for subjects learning under the successive procedure and suggested that, when the stimulus appears alone, subjects are likely to focus on a salient or dominant aspect of its meaning and then will incorporate the response into the predominant meaning domain of the stimulus. On the other hand, the simultaneous procedure may encourage an

Requests for reprints should be addressed to Lynn Hasher, Department of Psychology, 8 Weiss, Temple University, Philadelphia, Pennsylvania 19122. We would like to thank Marlane Edelman for her assistance. interpretation of the stimulus which is determined by the response and hence, on the average, should involve a more situation-specific interpretation of the stimulus than is the case when the stimulus plays a predominant role.

In the other study Hasher and Johnson reported, elaborators were collected from subjects learning two lists which stood in an A-B, A-D relationship to one another. The elaborators were then given to new subjects to use in learning a single list. First-list elaborators yielded higher recall scores than did second-list elaborators. Furthermore, post hoc ratings suggested that there were more stimulus-related elaborators among the firstlist pool than among the second-list pool, where there were slightly more response-related elaborators. Here also, Hasher and Johnson attributed the retention difference to the value of stimulus-related encodings of the pairs.

While this was a consistent interpretation of the results of these two studies, it was partially post hoc, and alternative interpretations of the results are possible. For example, first-generated or first-choice elaborators may be better or more stable than second-generated elaborators (e.g., Keppel, 1968; Postman, Stark, \& Burns, 1974), whatever the nature of the relation between the elaborator and the members of the pair. The present work is an attempt to further specify the impact of interpretive factors on forgetting by isolating the relative contribution to long-term retention of an elaborator's relationship to the members of a pair and its order of generation.

The experiment consisted of an elaborator-generation phase and a memory-task phase. In the elaboratorgeneration phase, subjects learned a list of pairs and were then asked to report the elaborators they used in learning the pairs. Following that, they were asked to provide a "second-choice" elaborator for each pair, one they might have used had they not been able to use the 
initially generated one. Each elaborator was then rated by the subject and by independent raters for the pair member (stimulus, response, or both) to which it was maximally related. In the memory-task phase of the experiment, new subjects each learned 12 pairs, each of which had an elaborator chosen from those provided by subjects in the first phase of the experiment. There were four conditions, differing only in the source of the elaborators: These could be either first- or second-choice stimulus elaborators or first- or second-choice response elaborators. Subjects in each condition were tested for retention either immediately after the end of learning or 1 week later. If our interpretation of the previous experiments was correct, stimulus-related elaborators should produce better retention than response-related elaborators.

\section{ELABORATOR-GENERATION PHASE}

\section{Method}

Materials. Two 12-pair lists were constructed by choosing nouns of both high-meaningfulness (range 6.44 to 8.16 ) and high-imagery (range 5.07 to 6.83 ) values (Paivio, Yuille, \& Madigan. 1968). Across the two lists, the average values for meaningfulness and imagery were 7.18 and 6.31 , respectively. The words were of moderate frequency values, ranging from 13 to 29 per million, with a mean of 21.25 (Thorndike \& Lorge, 1944). Items were paired randomly, except that meaningful similarities among items within a list were minimized. Each pair was typed and centered on $5 \times 8$ in. cards. For test trials, only the stimulus member appeared and it was typed in the position it occupied on the study-trial card, together with a blank space for the missing response term.

Four study- and test-trial orders were derived by assigning items to positions randomly with two constraints: (1) An item could occupy the first or last position on either a study or test trial no more than twice; (2) an item which was last on a study trial could not be first on the next test trial and vice versa. Each list was learned by an equal number of subjects.

Procedure. Subjects were instructed about the study-test paired associate procedure prior to spending a short time practicing turning blank cards at the 3-sec rate used for both the study and the test trials. A tape recording of clicks allowed the subject to pace himself. Prior to acquisition, subjects were informed about the usefulness of elaborators as a learning device and were given an example using a pair of words that was not on the list. They were instructed that their task was to learn the words, but that they should try to be aware of using elaborators because we would ask for them at the end of learning.

When the subject reached the criterion of one perfect test trial. an unpaced questionnaire was administered. Each pair was read to the subject and she/he was requested to report the elaborator she/he had actually used. Subjects were instructed to try to phrase the elaborator in one word. Then the subject was asked to go through the list a second time and give a secondchoice elaborator for each pair, that is, the one she/he would have used if, for some reason, she/he had not been able to use the first choice. Next, the experimenter read each pair with the first-choice elaborator and asked the subject whether it was related to the stimulus, the response, or equally to both. This procedure was repeated for each pair together with its secondchoice elaborator. Subsequently, two independent raters performed the same classification task, so that the criterion for relatedness would be the same across all elaborators generated by different subjects. Thus, three people rated each elaborator.
Table 1

Number of Elaborators in Each of the Four Relations to the Pairs

\begin{tabular}{lcccc}
\hline & \multicolumn{2}{c}{ Nature of the Classified Relationship } \\
\cline { 2 - 5 } Elaborator Type & $\begin{array}{c}\text { Stimulus } \\
\text { Term }\end{array}$ & $\begin{array}{c}\text { Response } \\
\text { Term }\end{array}$ & $\begin{array}{c}\text { Both } \\
\text { Terms }\end{array}$ & $\begin{array}{c}\text { Unclass- } \\
\text { ifiable }\end{array}$ \\
\hline First-Generated & 88 & 64 & 16 & 8 \\
Second-Generated & 74 & 75 & 13 & 2 \\
\hline
\end{tabular}

Subjects Sixteen introductory psychology students participated individually in this portion of the experiment, for which they received course credit.

\section{Results}

Subjects took an average of 5.69 trials to reach criterion. Across both lists, the average number of pairs for which first-choice and second-choice elaborators were given was 11.06 and 10.50 , respectively. The slight decline from first-choice to second-choice elaborators was produced entirely by 3 of the 16 subjects. Usually, if one elaborator was generated, a second was also.

An item was assigned to a relational category when two of the three raters agreed in their classification decision, otherwise it was considered unclassifiable. Five elaborators, one first choice and four second choice, were not rated by the independent raters. Two were not rated because they were clearly obscene, three because of an experimenter error. The number of elaborators falling into each of the major classification categories may be seen in Table 1.

Hasher and Johnson (1975) reported that elaborators generated for a first-learned list (A-B) were more likely to be related to the stimulus member than were elaborators generated for a second-learned list (A-D). In the present instance, an analogous finding was obtained when the subjects were asked to generate two elaborators for a single list: First-choice elaborators were more likely to be related to the stimulus term than to the response, while second-choice elaborators appeared equally likely to be related to either the stimulus or response members of a pair.

\section{MEMORY-TASK PHASE}

While the change in the nature of the elaborators is interesting, it takes on added importance in light of the influence these elaborators might have on long-term retention. While Hasher and Johnson (1975) argued that the retention advantage shown for first-generated elaborators was due to the greater frequency of stimulusrelated elaborators, it is of course possible that this advantage was due to some other, uncategorized, aspect of the elaborators, or to a combination of this unknown factor with characteristics of the materials. The second portion of this study represents an attempt to isolate the independent contribution to retention of two factors: first- vs. second-choice elaborators and stimulus- vs. response-rela ted elaborators. 


\section{Method}

Materials. The two 12-item paired associate lists used in the elaborator-generation phase of the study were also used in this phase. Four unique pools of elaborators were obtained from the rating data: first-choice/stimulus-related, first-choice/responserelated, second-choice/stimulus-related, and second-choice/ response-related. Two elaborators from each pool were chosen to go with each pair. The particular elaborators were selected by two experimenters on the basis of their being the "best" representative of their classification. Thus, within each of the four elaborator conditions of the experiment, two paired associate lists, each with two unique sets of elaborators, were used.

On study trials, elaborators were enclosed in parentheses above and centered between the stimulus and the response terms of each pair. On test trials, only the stimulus terms appeared.

Procedure. Subjects learned a single list by the study-test method to a criterion of 9 out of 12 correct. The task was again paced at a 3-sec rate by recorded clicks. Subjects turned through the cards themselves after practicing with blank cards. Prior to the beginning of the task, instructions were read that explained the nature of the paired associate task and the usefulness of the elaborators. Subjects were told that, while they might find the elaborators cumbersome to use during learning, they should make every attempt to do so, since the elaborators would help them remember the pairs longer than they would be able to without using elaborators.

Retention was tested either immediately or a week later. The same testing procedure was used after both intervals. On three successive trials, subjects turned through a deck of stimulus terms at a 3-sec rate and tried to recall the appropriate responses. No feedback was provided.

Subjects. New subjects participated in the second phase of the experiment, 12 in each of the four immediate retention conditions and 16 in each delayed retention condition. They were randomly assigned to conditions and were tested individually. Most subjects received course credit for participating and some subjects were volunteers solicited during the summer term.

\section{Results}

Acquisition. The overall mean number of trials to reach criterion was 5.50 and the mean number correct on the criterial learning trial was 9.71 . The 2 by 2 by 2 analyses of variance on these two measures revealed no significant sources of variation; thus, both learning speed and terminal level of performance were considered equivalent across all conditions.

Retention. Protocols were scored for both the number of items recalled and the number of items lost. This latter measure, calculated by subtracting each subject's retention performance from his criterial performance, takes into account whatever slight deviations there may have been in individual levels of learning. In addition, two variants of each measure were calculated: one a stringent measure, the other a lenient measure. To be correct under a stringent criterion, a response must be paired with its appropriate stimulus term. Under a lenient recall criterion, response terms from the list are correct independent of the stimulus with which they are paired. For loss scores, the criterion (stringent or lenient) used on the retention test was also used on the terminal learning trial. Analyses were conducted on each of the four retention measures. Because the results were nearly identical for all the analyses, only one will be described in detail-that for stringent recall. The means contributing to this analysis may be seen in Figure 1.

Significant forgetting occurred across the week's retention interval $[\mathrm{F}(1,104)=314.52, \quad \mathrm{MSe}=3.00]$. While the main effect of type of elaborator showed an overall advantage for stimulus- as compared to responserelated elaborators $[F(1,104)=11.31]$, this variable also entered into a significant interaction with time $[F(1,104=11.25]$. As can be seen in Figure 1, lists learned with stimulus-related elaborators were forgotten more slowly than were lists learned with responserelated elaborators. The order in which an elaborator was generated did not produce a significant main effect $(F<1)$, nor did order interact with time $(F<1)$ or with type of elaborator $(F=1.76)$.

Across the three successive recall trials, several interesting results were observed. First, performance improved despite the fact that no feedback was provided $[\mathrm{F}(2,208)=15.78, \mathrm{MSe}=.45]$; however, it did so more pronouncedly at the delayed test of recall than at the immediate test $[F(2,208)=6.81]$. Here is also the strongest suggestion of any advantage first-choice elaborators may have over second-choice elaborators. There is an interaction of borderline significance of order of generation of elaborators with trials $[F(2,208)=2.84$, $\mathrm{p}<.06]$. Across analyses on the four measures of recall, this effect actually attained significance on only one, that for stringent loss scores; however, its probability value was always between .05 and .07 . First-choice elaborators appeared, then, to boost recall across successive test trials more than did second-choice elaborators.

Overail, the data provide strong evidence for the efficacy of a stimulus-elaborated as compared to a

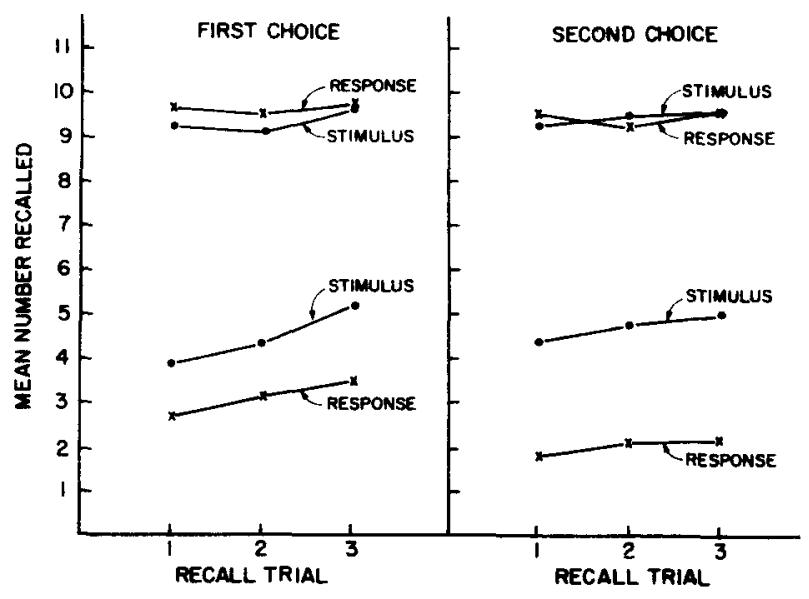

Figure 1. Mean number recalled across the three successive recall trials. The left panel represents recall for subjects learning with first-choice elaborators (stimulus- or response-related), the right panel, recall for second-choice elaborators (stimulus- or response-related). In both panels, the upper two curves represent immediate recall performance, while the lower two curves represent delayed recall performance. 
response-elaborated encoding in the long-term recall of arbitrary pairs of words. There was also some evidence that first-generated elaborators, whether related to the stimulus or to the response term, are better than secondgenerated elaborators.

\section{DISCUSSION}

In the present experiment, stimulus-related elaborators produced better long-term retention than did response-related elaborators. What is the nature of the advantage conferred by a stimulus-related encoding? We believe that an elaborator that is anchored to a stimulus term is most likely to sample the core, or least situationspecific, meaning of the cue. Core semantic properties are those aspects of meaning which are consistently relevant across occurrences of a concept. That stimulusrelated elaborators are more closely tied to core meaning must certainly be true compared to response-anchored elaborators whose relation to the stimulus cue must be highly artificial or situation specific, given the arbitrary nature of the pairings used as study material. The closer the encoding of a unit is to the core meaning of the stimulus, the more likely it is to recur when the cue is presented later. Consider two pairs from the present experiment: cradle-oats and umbrella-pudding. After a delay, the stimulus-tied elaborators, baby and rain, are far more likely to be suggested by the appropriate nominal stimulus than are the response-tied elaborators, cereal and chocolate. Stimulus-tied elaborators could thus be considered a "test-appropriate encoding strategy" (cf. Lockhart, Craik, \& Jacoby, 1976), whereas responsetied elaborators are not.

Although this argument includes the assumption that all memories are potentially available under appropriate reinstatement conditions, it is also possible that elaborators which utilize the most salient aspects of the meaning of a cue are less subject to disruption than are encodings involving more tangential or optional aspects of word meanings. In any event, the overall importance of the understanding of memory processes of the notion of "semantic distance from the core" receives additional support from recent findings (Hashtroudi \& Johnson, 1976). These indicate that the ease with which a subject can return to an initially assigned interpretation of a stimulus (and so recall the response) varied with the nature of the interpretation assigned to that same stimulus in a second list. It is more difficult to return to the initial interpretation of the stimulus when a subsequent interpretation involves highly salient aspects of the meaning of the stimulus as compared to less central aspects of potential meanings.

The present results are consistent with previous work (e.g., Light \& Carter-Sobell, 1970; Tulving \& Thomson, 1973 ) indicating that a change in context between acquisition and retention may reduce the probability that a subject will remember that an item was on the target list. In those cases, the context presumably deter- mined the semantic encoding of the item. It should be noted, however, that the data from the elaboratorcollection phase of the present experiment shows that the same contextual conditions can lead to more or less context-specific (in this case, how tied an elaborator is to the response term) encodings. Clearly, encoding specificity is not an automatic and invariant consequence of the experimental situation. In addition, how context specific an encoding of an item is has implications for long-term retention. The retention data suggest that the probability of the appropriate semantic encoding's being recovered depends on the extent to which the original interpretation deviated from the core or most salient aspects of the meaning of the stimulus.

Thus, rather than assume that there are two separate memory stores, episodic and semantic, and that the principles of forgetting are different for the two (Tulving, 1972), we prefer an analysis based on a single memory in which information is assimilated in to previously established conceptual categories or meanings in varying degrees of closeness to core semantic properties. In remembering, all other things being equal, the core is the most likely "entry point" for a given cue. In the present study, the major differences in retention were produced by a manipulation (stimulus-vs. responserelated elaborators) that presumably resulted in wide degrees of difference in deviation from core meaning. A smaller difference was seen for first- vs. second-choice elaborators, presumably because average deviation from core was smaller here, although less so among firstchoice than among second-choice elaborators.

It should also be noted that the present study, like many others, reveals a discrepancy between the variables that influence acquisiton (performance on immediate recall trials) and those that influence retention (performance on recall trials after a substantial interval). Here, the type of elaborator did not affect the rate at which pairs were learned (the mean trials to criterion were 5.28 and $5.75, F<1$, for stimulus-related and responserelated elaborators, respectively), but did have a marked effect on retention. The more typical finding is one in which there are clear acquisiton differences and no attending retention differences. Thus, the encodings and/or mnemonic devices that function at immediate recall and those that function at a delay are not necessarily the same. Our research suggests that encodings within a wide range of semantic distance from the stimulus will be adequate during acquisition, perhaps because other attributes (e.g., frequency, recency, multiple encodings) may help to maintain item availability. However, over time, the reinstatement of a memory appears to depend upon the specific semantic characteristics of the encoding.

\section{REFERENCES}

Forbes. E. J., \& Reese, H. W. Pictorial elaboration and recall of multilist paired associates. Joumal of Experimental Psychology, 1974, 102, 836-840. 
HASHER, L., \& Johnson, M. K. Interpretive factors in forgetting. Journal of Experimental Psychology: Human Learning and Memory, 1975, 1, 567-575.

Hasher, L., \& Thomas, H. A developmental study of retention. Developmental Psychology, 1973, 9, 281.

HASHER, L., RIEBMAN, B., \& WREN, F. Imagery and the retention of free-recall learning. Journal of Experimental Psychology: Human Learning and Memory, 1976, 2 , 172.181.

Hashtroudi, S., \& Johnson, M. K. Transfer and forgetting: Interpretive shifts and stimulus reinstatement. Journal of Experimental Psychology: Human Learning and Memory, 1976, 2, 262-272.

KePpel. G. Retroactive and proactive inhibition. In T. R. Dixon \& D. L. Horton (Eds.), Verbal behavior and general behavior theory. Englewood Cliffs, N.J: Prentice-Hall. 1968.

Light, L. L., \& CARTER-Sobell, L. Effects of changed semantic context on recognition memory. Joumal of Verbal Learning and Verbal Behavior. 1970, 9, 1-11.

Lockhart, R. S., Craik, F. I. M., \& Jacoby, L. L. Depth of processing, recognition and recall. In J. Brown (Ed.). Recall and recognition. London: Wiley, 1976.

Olton, R. M. The effect of a mnemonic upon the retention of paired-associate verbal behavior. Joumal of Verbal Learning and Verbal Behavior, 1969, 8, 43-48.
Paivio, A., Yuille, J. C., \& Madigan, S. A. Concreteness. imagery and meaningfulness values for 925 nouns. Journal of Experimental Psychology Monograph Supplement, 1968, 76(No. 1, Part 2).

Postman, L., Stark, K., \& Burns, S. Sources of proactive inhibition on unpaced tests of retention. American Journal of Psychology, 1974, 87, 33-56.

ThORNDIKE, E. L., \& LoRGE, I. The teachers' word book of 30,000 words. New York: Columbia University, 1944.

Tulving, E. Episodic and semantic memory. In E. Tulving \& W. Donaldson (Eds.), Organization of memory. New York: Academic Press, 1972.

Tulving, E., \& Thomson, D. M. Encoding specificity and retrieval processes in episodic memory. Psychological Review, 1973, 80, 352-373.

UNDERWOOD, B. J., \& RICHARDSON, J. The influence of meaningfulness, intralist similarity and serial position on retention. Journal of Experimental Psychology, 1956, 52, 119-126.

(Received for publication February 23, 1976; revision received June 14,1976 .) 